\title{
Novelty genesis: the mechanism of forming the new from the old
}

\author{
Dmitry Smirnov \\ ORCID ID: 0000-0003-4867-9000 \\ dmitry.smirnov@skolkovotech.ru
}

Melkor... had been given the greatest gifts of... knowledge... He had gone often alone into the void places seeking the Imperishable Flame; for desire grew hot within him to bring into Being things of his own.

—J.R.R. Tolkien. The Silmarillion, p. 3

\begin{abstract}
The theory of innovation and creativity has attempted to define the origins of novelty genesis using the concepts of bisociation, random mutations, exploration and play, equilibration of differences, and others. Despite recent attempts, there is still a gap in the theoretical description of how novelties emerge in a physical world. Is it a mysterious act or a phenomenon with clear logic to it? This conceptual article proposes a model for novelty genesis that describes the underlying mechanics of creative actions, both cognitive and physical. The research methodology is based on theory-building using case study research. Five familiar cases of novel creations are evaluated for cross-case patterns and similarities. The cases include cooking a dish, making a painting, creating a sculpture, childbirth, and the formation of a space star. The theoretical contribution of this paper is an alternative frame of reference to the mechanism of novelty genesis. The findings of this work might be of interest to academicians and practitioners in innovation studies. The model of novelty genesis put forward in this conceptual paper offers a new lens to understand how the formation of the new occurs.
\end{abstract}

Keywords: business, innovation process, creativity, novelty

\section{Introduction}

\subsection{Innovation process models}

This conceptual paper aims to advance the theory of innovation processes by building new theoretical perspectives on the genesis of novelty from case study research. The literature on innovation is voluminous (Kotsemir et al., 2013), so why is there a need for more theory? A short answer is because the 
existing innovation literature accounts fail to explain basic principles of novelty generation - the transition process from the old to something new. The following introductory sections aim to establish this gap.

The innovation process is commonly understood as generating and implementing new products or processes (Meissner \& Kotsemir, 2016). Innovation literature describes the formation of the new using various terminology, depending on the context and scale: "fundamental transition", "variation", "discontinuity", "radical change", or "incremental change" (Tushman, 1998). In a broader classical philosophical tradition, it has been described as "creation", "novelty", "emergence", or even "evolution" (Shiller, 1930). I adapt the term "novelty", which, according to Shiller, "is the simplest and the free-est from pomposity and contamination by irrelevant issues". Accordingly, the object of this study is the novelty generation process, which is defined as the transition from something old or known to something new or unknown. In the following sections, I use the terms "novelty generation", "novelty formation", or "novelty genesis" interchangeably to avoid monotonous repetitions.

Given multiple literature studies on conceptual innovation processes and different existing terms for novelty formation, one presumably should be capable of finding answers to the following questions. What is the fundamental mechanism that enables the formation of novelty? How is it possible that from the old, something new emerges? Under what conditions and principles is there a transition from the existing products and processes to the innovative ones? Several recent literature reviews have systematised numerous models of the innovation process found in the literature. I survey them below to find answers.

The study of Herstatt and Verworn analysed various innovation process models (Herstatt \& Verworn, 2004). Many models utilise the concept of phases: phase-review-process, stage-gate-process, normative process model, simultaneous development phases, Thom's three-phase model, and process model including failures. These models consist of a sequence of phases with a general title for processes at each stage. The answer to the riddle of the novelty-generation mechanism is typically hidden behind titles such as "concept phase", "definition phase", "idea formulation", "idea generation", "product definition", “concept development", “concept generation". In other words, the models do not discuss how exactly a novel idea, concept, product are generated. It is assumed that the novelty is created somehow behind the veil of those phases.

Eveleens has analysed 12 innovation process models identified in the literature between 1962 and 2008 (Eveleens, 2010). Based on the findings, he has conceptualised six common phases of the innovation process. They include idea generation, selection, development and testing, implementation and launch, post-launch, and learning. The formation of novelty during idea generation characterized by different authors as "opening up of possibilities", "divergent behavior", "new combinations", "generation of possibilities", "crystallization", "variation". One can generalise this process as the change that consists of new combinations and leads to the crystallisation of new outcomes and possibilities. However, this theorisation is still inadequate because it does not explain the necessary conditions for the variation process. 
Meissner \& Kotsemir help to advance further the conceptual understanding by analysing papers about innovation process and models between 1963 and 2013 cited more than 200 times (Meissner \& Kotsemir, 2016). Their survey identified six consecutive generations of conceptual innovation models: black-box model, linear model, interactive models, system model, evolutionary model, and innovation milieu model. Most of these models do not fit our purposes because they focus on the mesoscale environment of innovation - inter-organisational and regional factors and activities. However, some of the models offer relevant insights. They include the black-box model, the linear model, and the interactive model discussed below.

The black box model postulates that the source of innovation cannot be explained by changes in capital or labour but rather by technological advances. However, the model also assumes invisibility of what happens when investing in science and technology. It only highlights the importance of inputs and outputs of the black box. This representation might explain why the exact mechanics of novelty generation is inadequately addressed in the literature. However, it also offers a valuable insight that the innovation process needs inputs that somehow are converted into outputs. This approach puts forward curious questions. Should there be the conservation of what was put inside the black box and what left it? Does the innovation process follow physical laws of conversion of mass and energy? If it does not, from where exactly does the new emerge?

The linear model assumes a step-by-step process from the idea to implementation. Linearity is the underlying feature of the models studied by Herstatt and Verworn and the six-phase process conceptualised by Eveleens. As discussed previously, these models do not offer an adequate description of the novelty generation process and related conditions.

According to Meissner \& Kostemir, interaction models moved away from linearity and postulated that "the innovation process can also be circular (iterative) rather than purely sequential." However, the authors continue, "the interactive models still did not specify the driving forces for the innovation engine." The observation about circularity offers a compelling insight. It implies that planning and goal setting might conflict with the underlying uncertainty and contingent properties of the activities involved in the innovation process. This observation is confirmed with empirical data, which will be discussed shortly.

Other surveys of innovation process models have made similar findings to the ones analysed above and did not identify the mechanisms that govern the process of novelty generation (Lopes et al., 2012; Dieter \& Schmitt, 2018).

Another lens to study the innovation process is related to the resource-based approach (Bates \& Flynn, 1995). For example, Sarasvathy argues that the innovation process might follow two types of logic: causal and effectual (Sarasvathy, 2001). She writes:

Causation processes take a particular effect as given and focus on selecting between means to create that effect. Effectuation processes take a set of means as given and focus on selecting between possible effects created with that set of means. 
In other words, causation logic begins with a business goal and works out ways to reach that goal. For example, an entrepreneur would identify a target customer and his perceived or latent needs through the market definition, segmentation, targeting and positioning. The entrepreneur would then create a product to meet the needs of the target audience. Effectuation logic begins with questions: Who am I? What do I know? Whom do I know? What resources do I have? The entrepreneur then considers possible markets, identifying strategic partners and opportunities through contingent and experiential learning. This process would converge from several strategic options to a particular set of customers and a product for them. The main contribution of the causal and effectuation logic to the understanding of novelty generation is the description of a two-way logical link between the result and the optimised resources to achieve it. However, neither causal nor effectual logic clearly explain how exactly and why products become novel.

The gap in the understanding of principles, mechanisms and elements of novelty generation have also been identified by other authors. Gupta recently analysed 115 recent research papers about innovation models and their underlying theories and concluded:

Rogers' diffusion theory, ambidextrous theory, dual core theory, theory of radicalness, four factor theory, interactionist theory, and componential theory ... fail to explain how innovation can come about (Gupta, 2018)

Mendoza-Silva analysed 137 research papers that considered innovation capability as the ability to continuously transform knowledge and ideas into new products, processes, and systems (Mendoza-Silva, 2020). The author concluded that understanding the nature and the process of innovation capability remains one of many gaps in the pertinent literature.

Sossa and colleagues have reviewed 73 Scopus-referenced documents about innovation management models (Sossa et al., 2019) and concluded:

...innovation management models [IMM] do not readily show patterns that allow an organisation, institution or sector to have clear elements to start, identify or propose a model. Yet sectoral studies and company proposals are found. Most do not explicate the way they identified or prioritised model variables, nor their behaviour regarding information and knowledge flows among the activities that make up their IMM, nor the way in which its dynamics or its evolution can be understood in time.

So far, the innovation literature has provided scarce answers to the questions that I put forward at the beginning of this section. Why is that? Is the emergence of novelty a mystery beyond comprehension? Is it a random and unmanageable process? The innovation literature has treated the genesis mechanism of novel ideas, technologies, products and processes as a black box-a randomiser or variation machine that uses different inputs and produces novel outputs. Is this the legacy of the black box innovation model or the assumption that novelty genesis depends on a particular field?

Some insights can be still derived from innovation studies. As the analysis of different innovation models showed, the generation of novelty is associated with a new combination of elements through a 
linking mechanism into the crystallisation of new forms. The crystallisation process is iterative and influenced by contextual factors. The input components and survivability of the outcomes are subject to the innovation environment and conditioned by technological trajectories and selection forces (Tushman, 1998; Meissner \& Kotsemir, 2016). In Fig. 1, I summarise and conceptualise the current understanding of novelty genesis in the innovation literature. However, the question remains: What is the underlying mechanism of the iterative novelty generator?

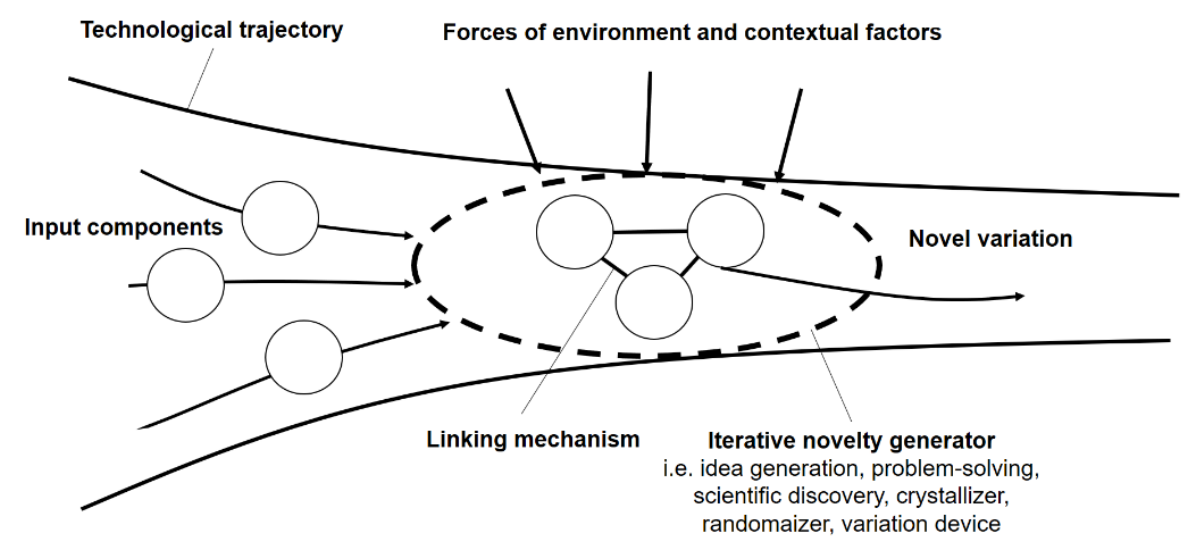

Fig. 1. Novelty generator according to the innovation literature

Creativity is frequently discussed in the literature as a capacity for creative acts that generate novelty. To understand this capacity better, the following section discusses main theories from the field of creativity.

\subsection{Review of creativity theory}

In a recent study, Walia summarised existing theoretical contributions in literature and synthesised a dynamic conceptual model of creativity (Walia, 2019). This model puts creative acts in the context of the social environment and describes the main reasons people engage in creation. The model focuses on the dynamic processes at a higher abstract level than the creation itself, whereby the latter is still rendered as a "black box".

Other works clarify the nature of the black box of creation. A fundamental study of Koestler analysed creative acts in humour, art and science (Koestler, 1964). These processes share a common aspect of the creative process, which Koestler called "bisociation". It combines elements from two previously unrelated cognitive matrices into a new matrix of meaning by making comparisons, abstraction, metaphors and analogies. Nonaka observed a similar pattern — through metaphor and analogy - in creating new knowledge (Nonaka, 1994). Sweller points out that the basis of creative acts is the generation of random mutations (Sweller, 2009). The author understands a random mutation as a variation between genomes.

At first glance, a random mutation might sound like a mysterious, almost magical process: The great randomiser! But let us take a closer look. For a mutation to occur, there must be a preconceived

[PREPUBLICATION DRAFT: PLEASE, DO NOT CITE WITHOUT AUTHOR'S PERMISSION] 
combination of components. In the case of genomes, it would be an expected DNA sequence. This combination is preconceived because there is an instruction that genomes of original parts must recombine in a particular sequence. If this sequence is broken and there is a variation, then the resulting mutation is new and unexpected. By randomness, it is also assumed that the error in the sequence is uncontrolled and might happen unexpectedly. Suppose similar thinking is applied to the emergence of new ideas. In that case, an unexpected error or variation would result in a novel cognitive construct.

Boden generally discards the idea of random variations and puts forward the theory of play and exploration. She writes how creative individuals:

...think in a disciplined manner: they may be playful, but they aren't merely playing around. When something of potential interest turns up as a result of their playfulness, they focus on it - accepting, amending and developing it in disciplined ways (Boden, 2004, p. 319).

Shkliarevsky offers a critical evaluation of the randomness theory and the theory of play and exploration (Skilarevsky, 2017). The former is criticised on the ground that it is impossible to demonstrate true randomness. The latter theory has some internal logical inconsistencies, according to Skilarevsky. In the first, the reasoning of Boden implies that creative individuals, by playing and exploring, inherently follow the desire for consistency and equilibration. But how can equilibration lead to the creation of disequilibrium? The second paradox is related to selecting the most fruitful creative idea by rational and conscious actions of creative individuals.

Shkliarevsky writes:

The only basis for making such selection is the knowledge possessed by the creator. But if in making these choices the creator relies on knowledge that he or she already has, then no creation is involved.

Then the author proposes a solution to these paradoxes by utilising some of Jean Piaget's works. He studied the emergence of intelligence in children. One of Piaget's studies implies that "equilibration of differences leads to the emergence of new and more powerful levels of organisation, i.e., to disequilibrium." Shkliarevsky also highlights the importance of regulating the creational process to stabilise the process and reflect on the creation results.

According to the discussed theories, a creational process is a part of a larger social environment. A creator is motivated by observations and social conditions to engage in a creative act. The essence of this act is forming a disequilibrium or something new, which fits the social environment or passes the test for effectiveness within it. The exact mechanism of forming the new might be explained by bisociations, random variations, disciplined exploration and play, or equilibration of differences and regulation.

Although this understanding of creation might explain some of the questions related to the creative acts, it primarily focuses on the generation of new ideas as cognitive constructs. For our purposes, this representation of creation is insufficient. The creation of innovative products and services indeed involves the ideation stage. However, as discussed previously, innovation happens during various stages, starting 
from ideas and finishing with complex physical systems. The latter do not abide by the laws of imagination and are conditioned by physical and market forces. What happens when a novel idea conflicts with physical or social laws? The following section considers some aspects of this relation for knowledge-intensive technical systems.

\subsection{Innovation and knowledge-intensive technical systems}

At present, common approaches among practitioners and some academics to the management of technology-based projects include three underlying assumptions. The first is that business goals condition technology (Porter, 1997). This assumption means that technology is considered inferior to product requirements and adapted according to business strategy. The second assumption is that if there is a conflict between business goals and technical capability, it could be resolved through the process of problemsolving and exploration (Utterback, 1971). The third assumption says that the cradle of innovative knowledge and ideas for problem-solving is scientific activities (Bush, 1945). Fig. 2 illustrates these three assumptions. The emerging evidence in literature challenges these presuppositions.

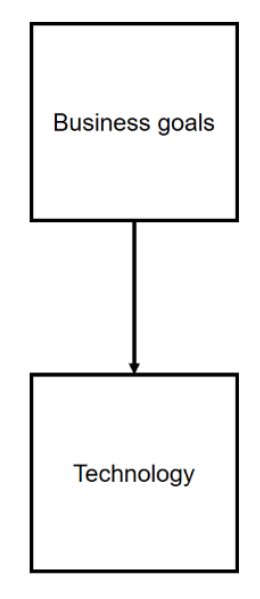

a)

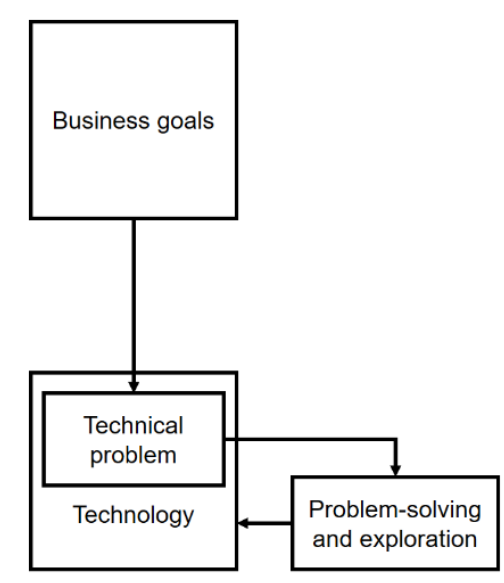

b)

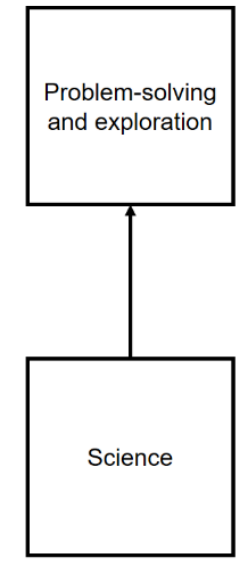

c)

Fig. 2. Common assumptions of technological innovation about technology: a) business goals condition technology, b) technical problems are resolved through problem-solving and exploration, $c$ ) scientific activities is the source of knowledge for problem-solving and exploration

A statistical study of $561 \mathrm{R} \& \mathrm{D}$ projects found that technological uncertainty is the second most statistically significant variable after the project expected profitability that determines commercial success of technology-based projects (Astebro, 2004). These findings mean that often technology conditions business goals. Factors related to technology affect strategy, market applications, and performance metrics of the product. They include the design decisions made at the early stages (Smirnov \& Golkar, 2015), the way those decisions were made by team members (Smirnov \& Golkar, 2019), and technical problems that might arise during later cycles of system testing (Smirnov et al., 2018). This evidence shows that, instead 
of simply fixing a technical issue, problem-solving and exploration might lead to different performance metrics and market applications. In addition, empirical findings (Dernis, 2016; Smirnov \& Willoughby, 2021) show that the origins of technical innovation lie within the domain of technological activities rather than in the realm of scientific work, as commonly believed. These findings imply that the faith in scientific activities to solve problems and identify innovative solutions might be misplaced. Technological activities - explorative and experimental by nature - might be better suited for creative problem-solving. Fig. 3 illustrates revisited assumptions of technological innovations. The role of technology in generating innovation capability is more complex than previously thought. This inherent coupling of technical properties with the business characteristics of technology-based products implies that the novelty generation mechanism should not only describe the process of idea generation. It should also account for complex and often conflicting relations between human creativity and the obduracy of technology and natural laws.



a)

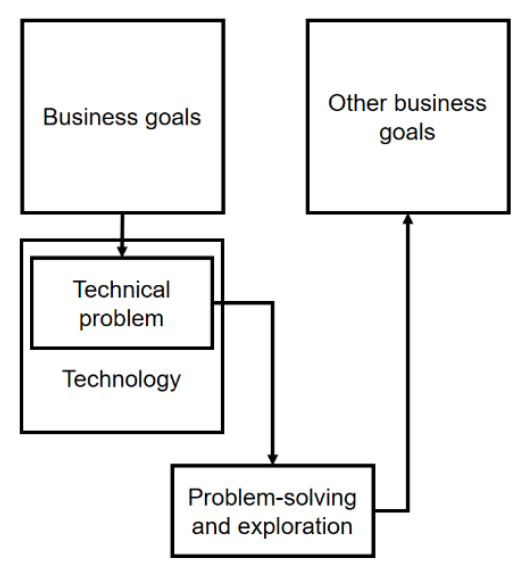

b)



c)

Fig. 3. Assumptions of technological innovation revisited: a) business goals and technology can condition each other, b) problem-solving and exploration leads to other business goals, $c$ ) technology is the source of knowledge for problem-solving and exploration

As stated at the beginning of this section, the mechanism underpinning novelty generation is not fully understood. To better conceptualise these processes, I would like to approach the transformation of the old to the new from a different perspective. I analyse different cases of creative processes, identify cross-case patterns, and develop a more accurate conceptual model of novelty genesis. The rest of the paper is structured in the following way. Section 2 discusses the methodology for the case analysis and the model of creation. Section 3 discusses results and clarifies the topology of the novelty genesis model. Section 4 discusses how this model fits with other theoretical models in creativity and innovation, outlines future research directions and comments on limitations. Section 5 concludes with the main findings of this work. 


\subsection{Research design}

This conceptual paper aims to make a theoretical contribution to the innovation literature by advancing the understanding of novelty generation. As such, this paper is not empirical. The research design follows the general guidelines of Jaakkola for conceptual articles (Jaakola, 2020). The introductory chapter showed that the existing theories in innovation and creativity literature insufficiently address the focal phenomenon of innovation - the genesis of the new from the old. This paper provides complementary value in conceptualising this central phenomenon better. It asks a question: What is the underlying mechanism of novelty genesis? The paper's domain theory is an intersection of the innovation process models and creativity theories discussed in sections 1.1 and 1.2. The method theory is theory-building using case-study research (Eisenhardt, 1989).

The basic logic of generating the findings in this paper follows like this. The introductory section offered the analysis of innovation process and creativity models (domain theory) to understand the genesis of novelty (focal phenomenon). The results indicated that, at present, the conceptualisation of this focal phenomenon for innovation purposes is scarce and inadequate. To extend the theory, I propose to study several cases of creative acts and build a theoretical model by conceptualising the results of case study research (method theory). The analysis focuses on creations in the physical world beyond the mere generation of cognitive artefacts.

This conceptual paper aims to adapt the domain theory. It switches the level of analysis in the innovation process theory from phase sequences, environmental and contextual factors to the underlying mechanism of novelty formation. It also shifts the theoretical perspective from cognitive creations to creations in the physical world. By doing so, it offers a new theoretical lens. It can extend the existing innovation process and creativity theory to explain better the principles of novelty creation in a physical world. The theoretical contribution of this paper is an alternative frame of reference to the mechanism of novelty genesis.

\subsection{Selecting cases}

The underlying hypothesis of this work is that regardless of the type of creative acts, cognitive or physical, the process of novelty formation follows the same general principles. In other words, it does not matter whether the outcome of a creative act has a form of an idea or physical artefact, the underlying mechanics of novelty genesis is the same. This hypothesis allows for freedom in case selection. The sampling can include extreme cases, such as childbirth and the formation of the space star. It can also include commonplace cases, such as cooking a new dish, making a painting, or creating a sculpture. In all instances, the cases are commonly familiar and transparently observable. They also offer a good variety of creative acts that include both human-guided and natural creations. In all instances, I am primarily interested in novel acts and related processes. This analysis of reproductions and copies is outside my focus. 
My methodology excludes quantitative analysis of the cases. It employs qualitative evaluations only. The disadvantage of excluding quantitative analysis is the risk to be carried away by exciting but false impressions from the cases. This paper focuses on qualitative analysis due to space and other practical limitations and leaves quantitative corroboration for future research.

With my selection of commonly known cases and focus on qualitative analysis, I aspire to offer an engaging and vivid explanation of a complex phenomenon of novelty genesis. Mintzberg eloquently described the benefits of this approach:

For a while systematic data create the foundation for our theories, it is the anecdotal data that enable us to do the building. Theory building seems to require rich description, the richness that comes from anecdote... I believe that the researcher who never goes near the water, who collects quantitative data from a distance without anecdote to support them, will always have difficulty explaining interesting relationships (although he may uncover them) (Mintzberg, 1987, p. 587).

\subsection{Analysis of the cases}

My approach is inductive and holistic. I analyse five case studies that represent different creative acts. Based on identified similarities, I construct an abstract model of novelty genesis. The five cases are: cooking a dish, drawing a painting, making a sculpture, childbirth, and the formation of an outer space star. These cases are familiar and do not need further introduction. The main tactic for the analysis of sampled cases is the search for cross-case patterns and similarities. As a result of this analysis, several common categories are identified, and within-case information is linked to identified patterns across cases. These patterns are integrated into one conceptual model of novelty genesis or, for simplicity, the NG model.

This analysis rests outside creationism - the theological interpretation of creation as an act of God (Kraay, 2008). My goal is to understand novelty (or creation) when regarded as an act within the physical world. However, some questions and arguments put forward by the creationist tradition are insightful. They exude notable rhetorical temper and cannot be discarded simply as lacking scientific evidence. Their application might help to conceptualise better the theoretical perspectives of the novelty genesis model in future. In addition, the results of this paper could be utilised for a critical revaluation of the special creation within the creationist tradition. But this examination should be better completed elsewhere.

\subsection{Enfolding literature}

The resulting NG model and its theoretical perspectives are compared with extant theories in literature to examine the main similarities, contradictions, and reasons. Three subfields in domain theory are discussed. The first is the innovation process models analysed in Section 1.1 and represented in Fig 1. Then follows the creativity theory discussed in Section 1.2. And, finally, the relationship between innovation and knowledge-intensive technical systems is introduced in Section 1.3. I also comment on the similarity of results to chemical reactions and offer a brief discussion on how the NG model can be applied in practice. 


\section{Results}

Table 1 and Fig. 4 show the results of the case analysis. Each line of Table 1 represents a crosscase pattern. Case-specific information related to each line is depicted in columns. The general observation about novelty is that it is very similar to the synthesis of new chemical elements by analogy.

Novelty formation, in all cases, involves a set of equilibrium, solution-neutral, or stable components. They are stable because, in normal conditions, they are hard to combine. For example, for star formation, hydrogen molecules would not fuse in normal circumstances. The components undergo preparation under specific conditions. During this process, the elements get destabilised and become unstable components: they are better suited for the synthesis. Compare, for example, stable food ingredients in a raw form and clean and cut parts ready for cooking. The former can be stored for a relatively long time. The latter gets oxidised and start a chemical reaction with the ambient environment.

During the synthesis, the components are typically located in a safe and confined microclimatethe confinement - where the synthesis process occurs under stable conditions. For example, embryo growth occurs in the placenta and amniotic fluid. The star formation transpires within the vacuum space confinement. The painting is performed within a safe space between the canvas and the painter in studio settings. The unstable elements in confinement are exposed to a particular form of energy and mass inflows, which are necessary to synthesise components. Mass inflows consist of noncritical auxiliary components. For example, during cooking, mixed vegetables receive energy in the form of heat and an oil inflow to prevent the ingredients from getting burnt on the pan. Alternatively, a sculptor applies mechanical cutting to synthesise a new combination of matter and emptiness. Hydrogen atoms get accelerated under extreme heat and pressure conditions. In other words, a unique and stable combination of elements is impossible without supplement energy and mass inflows. In all instances, a catalyst is present during the synthesis. It is an element of the novelty formation process that does not get consumed during the synthesis. It plays an instrumental role, through which the inflow of energy and mass occurs during the synthesis. Elements get connected through a specific linking mechanism. Activation energy is required to create a new structure. It is a minimum necessary amount of energy to bind the elements into a new structure with the linking mechanism. The start of the synthesis can be characterised by a new unstable form or condition, synthesis ignition. The components are combined in a new stable product by converting mass and energy, resulting in structural change. Byproduct mass and energy are also created. Notably, the creational acts always follow the instructions. They define what and how components should be synthesised to create the product. These instructions might have the form of a child's genetic code, lines and shapes that artists follow, or physical laws that control the fusion reaction. Regardless of the exact form of such rules, the formation of a novel product follows instructions to obtain a specific product form. In the case of childbirth and the formation of a space star, instructions had been already developed. Unless a painter or sculptor makes a reproduction, instructions for novel creations are unknown and developed by the authors during the creation 
process of new paintings and sculptures. A creator attempts to construct the instructions to synthesise a stable product. This explorative exercise goes through experimentation and movement through the hermeneutic circle (h-circle) (Debesay, 2008). The latter is formed between the unstable product, different synthesis conditions and stable components. A novel product survives if it is stable under selective environmental forces.

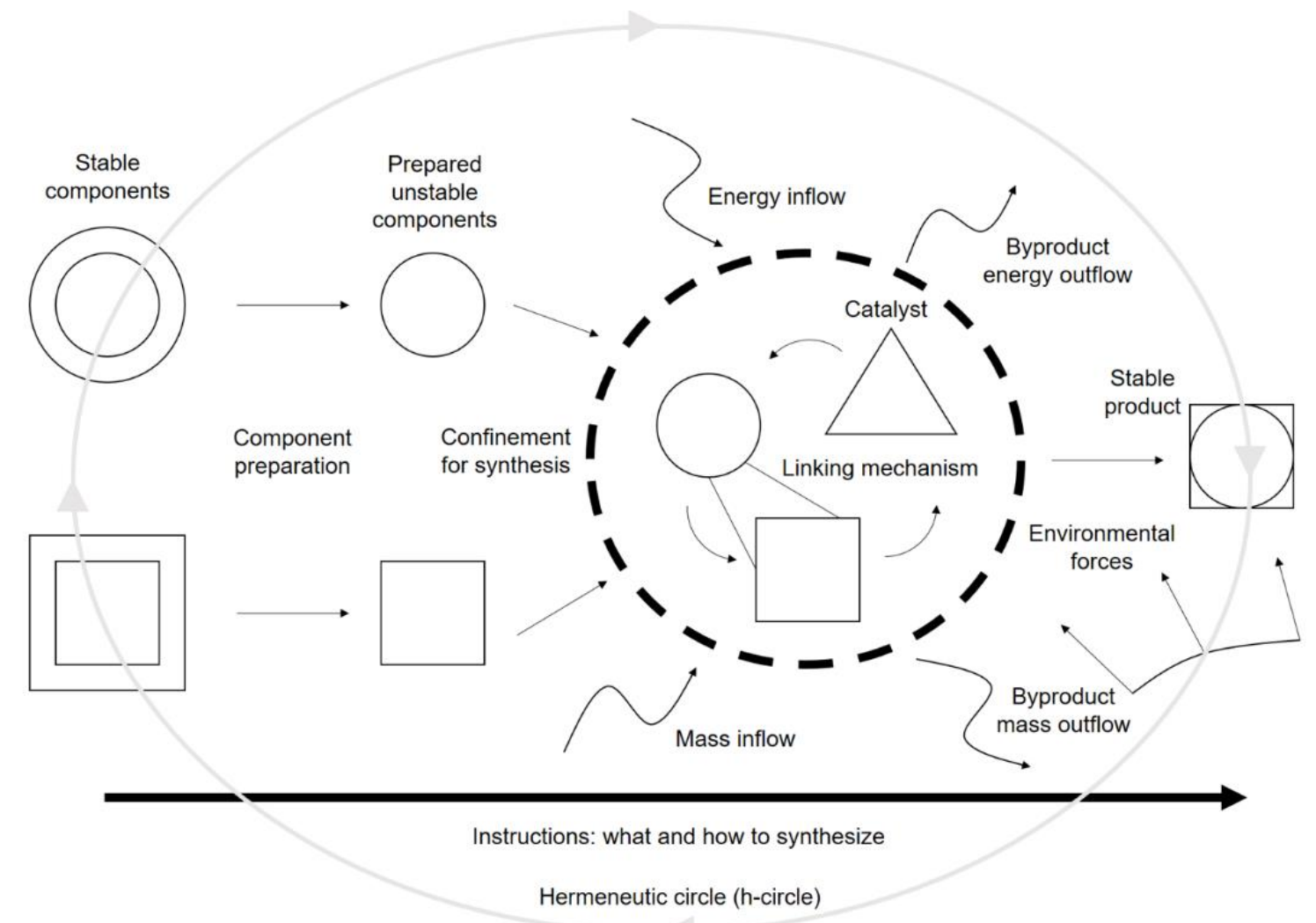

Fig. 4. Conceptual model of the process of novelty genesis 
Table 1. Analysis of case studies: similarities between creative act

\begin{tabular}{|c|c|c|c|c|c|}
\hline Name of the model part & Cooking a dish & Painting & Sculpture & Childbirth & Star formation \\
\hline $\begin{array}{l}\text { Equilibrium components or } \\
\text { reactants, hard to fuse }\end{array}$ & $\begin{array}{l}\text { Raw food ingredients, } \\
\text { water, other liquids }\end{array}$ & $\begin{array}{l}\text { Paper, canvas, paints in } \\
\text { the tube, water }\end{array}$ & $\begin{array}{l}\text { Solid material, light, } \\
\text { shadow and space }\end{array}$ & Male and female parents & Hydrogen atoms \\
\hline $\begin{array}{l}\text { Component preparation or } \\
\text { destabilisation }\end{array}$ & Wash, clean, cut & $\begin{array}{l}\text { Set up the canvas, put and } \\
\text { mix paints on the easel }\end{array}$ & $\begin{array}{l}\text { Selection and cutting of } \\
\text { the raw stone part }\end{array}$ & $\begin{array}{l}\text { Movement of the egg and } \\
\text { sperm cells through the } \\
\text { fallopian tube towards } \\
\text { each other }\end{array}$ & $\begin{array}{l}\text { Acceleration of two } \\
\text { hydrogen atoms }\end{array}$ \\
\hline $\begin{array}{l}\text { Confinement or } \\
\text { microclimate of } \\
\text { nourishment }\end{array}$ & $\begin{array}{l}\text { Pots, pans or other } \\
\text { cooking ware }\end{array}$ & $\begin{array}{l}\text { A studio or the space } \\
\text { between the canvas and } \\
\text { the painter }\end{array}$ & A workshop & $\begin{array}{l}\text { Placenta and amniotic } \\
\text { fluid }\end{array}$ & $\begin{array}{l}\text { Vacuum confinement of } \\
\text { outer space }\end{array}$ \\
\hline $\begin{array}{l}\text { Recombination of } \\
\text { components, binding }\end{array}$ & Cutting and mixing & $\begin{array}{l}\text { Mixing and applying the } \\
\text { paints on the canvas }\end{array}$ & $\begin{array}{l}\text { Different patterns of } \\
\text { material, voids, and } \\
\text { cavities }\end{array}$ & $\begin{array}{l}\text { Alignment of male and } \\
\text { female chromosomes }\end{array}$ & $\begin{array}{l}\text { Hydrogen atoms fuse into } \\
\text { helium }\end{array}$ \\
\hline Energy and mass supply & Heating & $\begin{array}{l}\text { A movement of the } \\
\text { painter's hand }\end{array}$ & Force to cut the material & $\begin{array}{l}\text { Heat. Nutrients supplied } \\
\text { through the yolk sac and } \\
\text { body stalk }\end{array}$ & $\begin{array}{l}\text { Extreme heating conditions } \\
\text { to accelerate hydrogen } \\
\text { atoms }\end{array}$ \\
\hline Catalyst & $\begin{array}{l}\text { Kitchen utensils and } \\
\text { equipment }\end{array}$ & $\begin{array}{l}\text { Supporting structure for } \\
\text { the canvas, easel, brush }\end{array}$ & The curving tool & Female body & Gravity \\
\hline Linking mechanism & $\begin{array}{l}\text { Direct contact of } \\
\text { components and } \\
\text { chemical reaction }\end{array}$ & $\begin{array}{l}\text { Paint dries out, variation } \\
\text { of colours and forms on } \\
\text { the canvas }\end{array}$ & $\begin{array}{l}\text { Sculpture's surface pattern } \\
\text { and light distribution at it. }\end{array}$ & Biological tissue & Collision and fusion \\
\hline Activation energy & $\begin{array}{l}\text { Heat to reach the } \\
\text { necessary cooking } \\
\text { temperature }\end{array}$ & Energy to apply paint & $\begin{array}{l}\text { Force needed to mend the } \\
\text { material }\end{array}$ & $\begin{array}{l}\text { Heat and chemical energy } \\
\text { to sustain the development } \\
\text { of the embryo }\end{array}$ & $\begin{array}{l}\text { Heat and pressure to } \\
\text { activate fusion of protons }\end{array}$ \\
\hline Synthesis ignition & $\begin{array}{l}\text { Applying heat, e.g. } \\
\text { Roasting, boiling, or } \\
\text { baking. }\end{array}$ & Applying paint & $\begin{array}{l}\text { The tool gets in contact } \\
\text { with the material to create } \\
\text { emptiness }\end{array}$ & Formation of zygote & $\begin{array}{l}\text { Formation of the ball of hot } \\
\text { gas (protostar) in the centre }\end{array}$ \\
\hline $\begin{array}{l}\text { Energy and mass } \\
\text { conversion, structural } \\
\text { change }\end{array}$ & $\begin{array}{l}\text { The phase change of } \\
\text { liquid and food } \\
\text { components, changes } \\
\text { in chemical structure. }\end{array}$ & $\begin{array}{l}\text { The paint is accumulated } \\
\text { on the canvas, and painter } \\
\text { converts his energy into } \\
\text { movement }\end{array}$ & $\begin{array}{l}\text { The mechanical energy of } \\
\text { the sculptor's tool goes } \\
\text { into heat and breaking of } \\
\text { the molecular bonds. }\end{array}$ & $\begin{array}{l}\text { Growth of cells guided by } \\
\text { gene instructions through } \\
\text { conversion of heat and } \\
\text { nutrients }\end{array}$ & $\begin{array}{l}\text { Gravity compresses atoms } \\
\text { together, generating heat } \\
\text { and pressure. Fusing } \\
\text { protons lose mass that gets } \\
\text { converted into energy. }\end{array}$ \\
\hline $\begin{array}{l}\text { New stable product, new } \\
\text { equilibrium state }\end{array}$ & $\begin{array}{l}\text { Food ready for } \\
\text { consumption }\end{array}$ & A painting & A sculpture & A baby & $\begin{array}{l}\text { A star with an equilibrium } \\
\text { of gravity force and fusion } \\
\text { explosions }\end{array}$ \\
\hline Byproduct energy and mass & $\begin{array}{l}\text { Smell, evaporation, } \\
\text { heat }\end{array}$ & Sketches, dried paint & Dirt and cut pieces, noise & Amniotic fluid & Energy, helium \\
\hline Instructions & $\begin{array}{l}\text { Recipe and cooking } \\
\text { process }\end{array}$ & $\begin{array}{l}\text { The direction of lines } \\
\text { (sketch), amount of paint, } \\
\text { paint mix }\end{array}$ & $\begin{array}{l}\text { Where and how to cut } \\
\text { material }\end{array}$ & $\begin{array}{l}\text { The information encoded } \\
\text { in male and female } \\
\text { chromosomes }\end{array}$ & Physical laws \\
\hline Hermeneutic circle & $\begin{array}{l}\text { Adjustment of heat and } \\
\text { ingredients for the right } \\
\text { taste and look }\end{array}$ & $\begin{array}{l}\text { Change in paints and lines } \\
\text { to make the expected } \\
\text { painting }\end{array}$ & $\begin{array}{l}\text { Modification of the } \\
\text { surface patterns to reach } \\
\text { the expected spectacle }\end{array}$ & $\begin{array}{l}\text { Change of characteristics } \\
\text { over successive } \\
\text { generations for survival }\end{array}$ & $\begin{array}{l}\text { Space-time singularity with } \\
\text { different possibilities of } \\
\text { physical laws }\end{array}$ \\
\hline $\begin{array}{l}\text { Selective environmental } \\
\text { forces }\end{array}$ & Taste preferences & Esthetic preferences & Esthetic preferences & Survival & $\begin{array}{l}\text { Heat expansion and gravity } \\
\text { compression }\end{array}$ \\
\hline
\end{tabular}




\subsection{Elements of the novelty genesis model}

a) Stable and unstable components

The first interesting aspect of the model in Fig. 4 is the difference between the stable and unstable components. Objects in the physical world generally are found in the equilibrium condition. By simply bringing them together, one cannot synthesise them. The same applies to stable ideas, which might be challenging to combine because of common sense, logical representation, or thinking conventions. Therefore, a stable component needs stabilising forms to be removed and be prepared for interactions with other non-equilibrium components. The interpretation of "non-equilibrium" depends on each specific case. For example, once food ingredients are opened or cleaned and cut, they tend to spoil faster. Alternatively, sperm and eggs are not stable for an extended period in childbirth and need a particular environment to survive. In other words, prepared unstable components are open for recombination. They are vulnerable to the external environment and various forces. But precisely because of this vulnerability, they are ideally suited for the synthesis reaction.

\section{b) Confinement}

The second interesting observation about the model is the unique role of confinement. The confinement is a safe and stable environment where the synthesis occurs. It appears to play a crucial role in the creational process. Within the confinement, supplement energy and mass are directed to the synthesised components. A painter creates a stable and intimate environment in his studio to synthesise a unique combination of colours and lines. Interruptions are not welcome, and unnecessary distractions are put aside. Tools and materials are kept nearby for convenience. Alternatively, nuclear fusion requires vacuum confinement, which outer space readily provides. A cook puts the ingredients in the pot and closes it to create perfect cooking conditions inside.

c) Catalyst

Catalyst is the third essential element. It may take a different form depending on the case. Tools of creators are catalysts that enable the recombination of components and the inflow of energy into the synthesis reaction. An artist might use various tools for the same purpose. Some might be more efficient than others. Gravity is instrumental in keeping hydrogen molecules close enough to heat and accelerate the atoms. 


\section{d) Linking mechanism}

The unstable components are combined under the supplement energy and mass into a new structure through a particular mechanism that links the elements together. Supplement energy and mass inflow are necessary to achieve a structural change within and between components to function as a new integral product. The linking mechanism could be a mechanical joint. In this case, the supplement energy is necessary to fix the components in the joint by a screwdriver, for example. The linking mechanism could be more subtle, for example, the variation of light and shadows on the surface of a sculpture. In this case, a sculptor must supply energy to remove the solid matter according to some predetermined pattern.

\section{e) Instructions}

The fourth essential part of the novelty formation process is instructions. They describe what components to choose, how to prepare them, what confinement to select, how much energy to use. In other words, instructions define whats and hows. Some forms of intellectual property-patents and trade secrets - describe and protect instructions. Instructions can be of different levels. For example, physical laws are basic instructions, and one cannot change them. A recipe for a new dish is a higher-level instruction. Lower-level instructions condition higher-level instructions: a cook can modify a recipe as long as it does not contradict the laws of physics. A creator might give instructions at the instance of synthesising components, like in the case of a painter. They also could be preprogrammed and operate independently from their creator. Examples include childbirth or the formation of a star. How do the instructions get developed?

In the latter examples of childbirth and star, without knowing who the author is, it is difficult to conjure the development process of instructions. For instance, if one subscribes to the scientific theory of evolution, then the childbirth instructions result from natural selection and genetic drift. But who or what does guide this selection? For cooking, an author of a creative act —or simply the cook-recombines ingredients during the preparation to reach the desired taste. The force that drives experimentation for a new dish and writes a resulting recipe manifests itself in the cook's actions. Which "cook" did guide the development of a "recipe" for childbirth? According to the theory of evolution, there is no artificial intention in the selection process. Therefore, the guiding action of a creator manifested itself in the influence of lower-level instructions - natural or physical laws. They are the creator that, for millions of years, adjusted and tuned the childbirth instructions. They define the limits of natural selection and, as a result, the "recipe" of the childbirth process. Physical laws developed a particular form of instructions: childbirth results from information exchange encoded in male and female chromosomes. But who or what created the physical laws? 
The consideration of physical laws as an author of instructions for childbirth is not against common sense; however, physical laws can also be instructions for forming an outer space star. Let us assume that the novelty genesis model holds for this scale of novelty creations. There remains a question, who or what did experiments with different particular forms of physical laws (or at least with varying values of physical constants) as instructions for creating outer space stars? Such experimentation (or random emergence?) continued until finally converging to a particular and invariant form of physical laws. This specific form led to the formation of stars as we know them.

Nevertheless, the definitive answer to the question of a creator of physical laws is moot. One "outrageous" possibility is that this "creator" is the state of spacetime singularity before the Big Bang. At that "moment", the physical laws, as we know them, were broken down. Different possibilities for physical laws existed. Perhaps, future research into symmetry principles might provide some answers to this question because symmetry principles "dictate the form of the laws of nature" (Gross, 1996).

Are the instructions material? Where are they stored? How do they get actualised? The gravitational phenomenon is one example of basic instructions. Objects with mass must attract one another. This instruction is a description of how mass and energy should be related. This instruction is not stored anywhere, but it defines how mass and energy get transformed. A painter moves his hand and presses a brush according to instructions. They can be stored in his head. They can also be generated at the moment of creation and being recorded in the painter's head. These instructions define how energy that moves the hand and masses of paints should be related. Future research might advance the understanding of instructions' nature. However, the analysed cases agree on one observation: novelty formation is the process of following the predetermined rules for the transformation of mass and energy. The creation of these rules appears to be an iterative process.

f) Hermeneutic circle (h-circle)

What does this model predict about the casualty of novelty formation? Should a creator first define the product and then figure out the components? Or one should start with parts and forecast what product is possible to synthesise with them? These two approaches are commonly referred to in the literature as casual (from the goal to components) and effectual or resource-based (from elements to contingent outcomes).

The model in Fig. 4 includes the h-circle between the components and the product. Developing instructions for synthesising a stable product within a given time and resources is a highly complicated matter. Think for a minute about cooking a new dish, previously unknown. What ingredients to choose? What form and taste should the final product have? Where to begin? An aspiring chef can start either from the components and explore what is possible to converge to a novel taste. Alternatively, he might start with 
an idea of the dish look and play with ingredients. Since there are no instructions, or in this case, a recipe, there is no certainty what the final product would look like, regardless of the casual or effectual logic.

A new product's creator might have a product goal or start with some available components to create something new. However, after experimenting with the synthesis process, a realisation might emerge that there are physical limits to what is possible to fuse or how much energy is necessary. Alternatively, the creator might realise that the resulting product has no market value (see below). Therefore a creator can not tell from the beginning what product he will create and what components he needs for the synthesis. The experimentation would oscillate between components and product preconceptions through the h-circle until a stable result is reached.

g) Selective environmental forces and value of the product

One way out of the hermeneutic circle of creation is the condition whereby the product obtains value. The creator decides to end the construction of instructions and stabilise the synthesis. This approach brings the question of novelty value. Should a novelty have an inherent value, or is the value imposed on the product after it has been created? The cases are not conclusive. Childbirth and the formation of a star follow the instructions that humans did not conjure, and as such, there is no inherent value preprogrammed to these creations, or at least we are not aware of such value. Humans impose value in those cases. However, a three-Michelin-star dish or an avant-garde painting might be created following preconceived values. For example, this value can be based on market research. In short, both situations are possible.

One observation that might explain the existence of a preconceived value for all cases, not just for cooking and art, is the idea of a stable product under the forces of the environment. If the product is not stable, it will not survive under environmental forces. This idea brings in the evolutionary notion of the selective force for the instructions and resulting novelties. This selective force is defined by the environment where the novelty is formed. If the product could survive this environment in a stable form, it has value. The notion of survival has a different specific meaning in each case but is similar at the abstract level. A new dish survives if it is tasty to other people, humans survive if, for example, they can maintain a healthy lifestyle and sustain themself independently. An outer space star does not explode if it can maintain a stable fusion reaction within the space environment. An interesting practical question is how to create a stable novel product under the selective forces of the environment?

h) Conservation laws

The NG model implies that any process of creation abides by the conservation laws. The basic idea behind this inference is the impossibility for a novelty to appear out of nowhere. It gets transformed from the existing resources. Strictly speaking, creation is not the emergence of the new; but a transformation of 
the old. Even ideas - products of cognitive dimension - it seems, must abide by this logic. Creativity to generate new ideas is based on synthesising old ideas in a new way under the inflow of energy (intellectual effort?). It starts with an identification of stable ideas that would become components. By "stable" ideas, I mean cognitive constructs (preferably written on paper or recorded in a digital form) that have logical consistency and represent accepted opinions or common sense. The transition from stable ideas to unstable ones would involve the acceptance by an individual that those ideas might be changed now. After this acceptance, ideas can be altered and recombined with other ideas. If an individual resists that another way to think is possible, it indicates a stable cognitive component. But once there is internal readiness to change common thinking, the creation of new ideas might proceed in the safe experimental confinement of a thought experiment or hand-written notes. Until there are doubts, logical inconsistency, missing elements to the combination of new ideas, the synthesis product is unstable. Once these issues are resolved, a new and stable idea emerges.

Perhaps, it is easier to see the application of the conservation principle with physical objects. Like in the chemical reaction, the sum of component mass and energy that enters the confinement must be equal to the sum of mass and energy that leaves the confinement. The application of the conservation principle might be more ambiguous to the cognitive creations. One might argue that a long time ago, there were no ideas. While humans have been creating new ideas, they have not destroyed the old ones. As a result, the space for new ideas has kept inflating. This proposition conflicts with the conservation principle put forward here. The latter seemingly suggests that the space of ideas is fixed, and we can only generate new ideas by breaking down the old ones.

The NG model connects the conservation in the physical and cognitive spaces. In other words, to generate new ideas, humans need an intake of energy or food from the physical world. The space of ideas has been inflating, at the cost of converting mass and energy from the physical world, so that humans can sustain intellectual activity. The model in Fig. 4 shows this intake of energy and mass. In addition, the storage of ideas is possible either in a brain or in some other storage. Inflows of energy and mass also sustain the creation and the operation of such storage. In other words, novelty is the transformation of energy and mass from the physical world.

\section{Discussion}

One notorious anecdotal example from popular culture illustrates the process in Fig. 4 vividly (Whale, 1931):

—Dead? Hey?

The physician checks the hand and positively nodes with his head.

-Quite a good scene, isn't it? One man crazy, three very sane spectators. 
Thunder in the sky. Frankenstein to Victor:

-Now?

-Yes!

—Adjust the batteries!

Deafening thunder. The body is lifted to the roof. Thunder again. Spectators are in fear. The body is brought back. Frankenstein in amazement:

—Look, it's moving!

Thunder.

—It's alive. It's alive. It's alive. It's moving. It is alive. It's alive. It's alive! It's alive! It's alive!

Frankenstein is hysterical. Spectators try to calm him.

- In the name of God, now I know what it feels like to be God!

The results depicted in Fig. 4 advance the understanding of the iterative novelty generator conceptualised from the innovation literature in Fig. 1. The process of novelty genesis might indeed seem a mysterious, even supernatural, act of creation. But a closer look reveals that the essence of this mystery is a structural change of unstable components under the inflow of energy guided by creational instructions. The following sections discuss the relation of the novelty genesis model to the domain theory of innovation processes and creativity.

\subsection{Relations to innovation process models}

I begin this section by comparing results to the chain-linked model of innovation (Kline \& Rosenberg, 1986). This model represents an advanced understanding of the innovation process among existing models reviewed by authors in the innovation literature. The chain-linked model was introduced to explain the black box of innovation as an alternative to the linear innovation model. According to the analysis of Kline and Rosenberg, the latter exhibited a number of shortcomings, such as the notion that innovation is initiated by research or the lacking explanation of cumulative learning about the product during the production process.

The basis of the chain-linked model is five main consecutive blocks or phases (Fig. 5-a), specifically "potential market" (1), "invent and/or produce analytic design" (2), "detailed design and test" (3), "redesign and produce" (4), "distribute and market" (5). These blocks are connected through feedback loops with the flow of information and cooperation. In addition, there are two special blocks, "knowledge"(6) and "research" (7), that feed the process of problem-solving.

This chain-linked model helps to resolve shortcomings of the linear approach to innovation processes. However, the complex links of information and cooperations between the blocks and the focus on the phases instead of the phase content make it exceedingly difficult to understand novelty formation's intertangled and complex nature (Fig. 5-b). Although the model's authors might not have aimed to describe novelty formation, one could still infer some implications. The model suggests that the innovation process is a complex web of iterations at different phases via various feedback loops. Once a firm explores the 
labyrinth of iterations, it develops a stable product. The novelty is assumed to be somehow acquired or generated during this exploration process through the sequence "design-build-test-redesign..." while also drawing from an existing body of knowledge or conducting research. Alas, the exact mechanism for novelty genesis remains hidden behind the block titles and the complex web of iterative feedback loops.



(a)

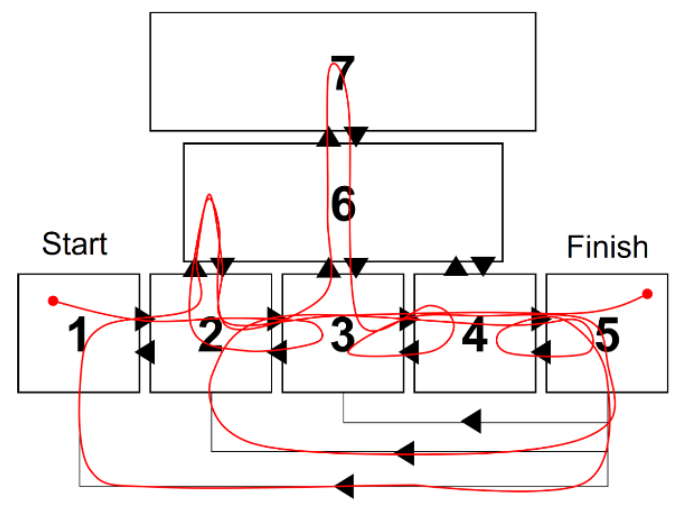

(b)

Fig. 5. The chain-linked model. Adapted from Kline \& Rosenberg, 1986. On the left: schematic view of the blocks and feedback loops. Arrows show the feedback direction. On the right: an illustration of the iterative development path highlighted with a red line. Numbers: 1) potential market, 2) invent and/or produce analytic design, 3) detailed design and test, 4) redesign and produce, 5) distribute and market, 6) knowledge, 7) research.

The model of novelty genesis offers a different lens to study the innovation process and proposes a different anthology of the elements. Instead of phases, it focuses on the components of the process and their interaction. This change of focus helps to understand better how novelty gets synthesised. The model of novelty genesis does not limit the process to go through the stages in Fig. 5. Instead, it allows for the interaction of components from different phases of the chain-link model simultaneously during synthesis. The novelty genesis model also explains how the novelty is created given the input parameters and the synthesis conditions.

When reviewing innovation process models and discussing the black-box model, I asked two questions: Should there be the conservation of what was put inside the black box and what left it? Does the innovation process follow physical laws of conversion of mass and energy? The novelty genesis model postulates that any input to the confinement, either in the form of the unstable component, or supplementary energy and mass, must be conserved. The innovation process must follow the physical laws of conservation of mass and energy. One seemingly problematic point of the model is the differentiation between tangible components, for example, a laboratory prototype of new technology, and intangible components, like the knowledge of the business team about a latent market need. To resolve this issue, I use the premise that intangible components or information does not exist without a storage medium. This means any information 
is supplied to the creational confinement on a storage medium as a mass. This storage could be a human brain or the hard drive of a computer. Inside the confinement, it gets converted into higher-level instructions of the product design by the creator. The remaining storage medium is moved out of the confinement as a byproduct mass. If the creator already possesses knowledge about perceived market needs, they might convert it immediately into instructions.

The representation of the novelty formation as a process with a set of input components, their transformed form, and conserved properties helps to study this process from a quantitative point of view. This conceptualisation opens new avenues to study novelty in future.

\subsection{Relations to chemical reactions}

One interesting observation about the NG model is its similarity to the processes observed during chemical reactions. A detailed comparison should be completed elsewhere, given the technical nature of such discussion; however, some general comments about similarities are in order. According to Oxford's English Dictionary (definition of chemistry, 2021), chemistry is the branch of science concerned with the substances of which matter is composed, the investigation of their properties and reactions, and the use of such reactions to form new substances [italics added for emphasis]. One might comment similarly about the results. The NG model describes components of which novelty is composed, the investigation of components' reactions, and the use of such reactions to form novelties. Stable components in the NG model are similar to reactants or reagents in a chemical reaction. The synthesis confinement is like the chemical reactor. Instructions resemble chemical equations. The intermediate products resulting from attempts to develop instructions and stabilise the reaction product are similar to transition states of a chemical reaction. The novelty formation is akin to the concept of chemical change. Physical laws, which are lower-level instructions, govern chemical reactions. A mix of lower- and higher-level instructions could control the formation of novelty. From the definition of chemical reactions, the goal of a chemist (a novelty creator) is to develop a chemical equation (instructions) that describes a chemical change (novelty formation), which results in substances in a chemical equilibrium (stable products). Future research might explore how to align better the NG model with extant quantitative and qualitative theories of chemistry, for example, the transition state theory (Truhlar et al., 1996), to describe the novelty genesis.

\subsection{Relations to creativity theories}

The novelty genesis model predicts that the environment where the creation stabilises in the form of a new product is where the product obtains its value. This prediction aligns with Walia's dynamic model of creativity (Walia, 2019), discussed previously. However, the work did not describe the process that occurs inside the black box. The proposed here model makes a theoretical contribution to fill this gap. 
According to Sweller, the source of creativity is the generation of random mutations and their test for effectiveness (Sweller, 2009). By applying the NG model proposed in this work, it is possible to show easily that such an error is not random. It is a conflict between instructions of different orders caused by the change in the energy and mass inflows into the confinement. Higher-order instructions, such as "recombine genetic material", are always conditioned by lower-order instructions. For example, "the energy of an incoming UV photon must be conserved during the interaction with the DNA molecule", which causes structural damage and molecular lesions. The instruction for the genomes to recombine in an expected sequence is higher-level instructions. The instruction that the process should abide by physical laws and mass and energy conservation is lower-level instructions - the synthesis occurs in confinement with energy and mass inflows. Suppose during the synthesis there is a change either in confinement or in energy or mass inflows (e.g. the incoming UV photon). In that case, there must be conservation at the level of basic instruction. However, the higher-level instruction-synthesis of DNA sequence-must continue. As a result, the final product is different because the boundary conditions of the synthesis changed. The scale of this synthesis is microscopic and difficult to control. However, it does not mean that it is random. So, the NG model postulates that the idea of randomness should not be applied to creative acts.

The results also explain how play and exploration (Boden, 2004) lead to novelty formation. The creations that follow the reproduction sequence have established instructions. However, if something new is created, the instructions do not exist, and a creator needs to experiment with the synthesis conditions to obtain a satisfactory result. Play and exploration is the process of constructing instructions. During this process, a creator plays with different components. For example, playfulness could be described by the readiness to amend stable ideas and concepts for cognitive creation. This is playful behaviour. The creator plays with ideas to create something new.

Shkliarevsky proposes that a novelty is the equilibration of differences under the regulation process (Shkliarevsky, 2017). The NG model predicts this outcome. The theoretical underpinnings of the model show that stable components enter the disequilibrium after the preparation and synthesis inside the confinement under energy and mass inflows. A new combination is generated and stabilised in a new product. This process can be regarded as "equilibration of differences". The act of constructing instructions that result in a stable product of synthesis implies a regulation procedure that at one moment begins to stabilise the synthesis. The NG model also resolves both paradoxes put forward by Shkliarevsky. The model shows how it is possible to create disequilibrium and stabilise a new product from the equilibrium of stable components. The NG also stipulates that it is impossible to possess knowledge about creations without creating first. This outcome follows from the requirement for the existence of new instructions. The latter must be developed before any creation. Creator's knowledge about the product is only a preconception based on the old knowledge, which says nothing about the formulated novelty. For example, try to create a 
radically new geometrical square. The first thing that comes to mind is an old square. Alternatively, try to make a fundamentally new frugramor. If one does not know what a frugramor is, there is no preconception for associations. The mind begins to find associations with the word parts from old knowledge to make sense of the word "frugramor". This shows that our mind can not possess knowledge about radically new things without creating them first. So the paradox is resolved by saying: The basis for making an initial selection about preconceived ideas is the old knowledge possessed by the creator. In making these choices, creators rely on old knowledge that they already have. New knowledge emerges during the synthesis experimentation (building instructions), and creation is involved.

\subsection{Relations to knowledge-intensive technical systems}

Fig. 3 depicted revisited assumptions of technological innovation. How does the NG model account for them? It considers technical components and business goals as stable and equal components of the synthesis process. The model postulates that the creation occurs according to instructions. However, if there is a conflict between basic instructions or physical laws that govern technology and higher-level instructions like the requirements to the product based on user needs, the synthesis into a stable product is not possible. This mechanism explains why sometimes technology conditions business goals. It also means that a creator must either change the higher-level instructions, which means other business goals or change the input conditions of the synthesis. The latter occurs through technological activities or explorative experimentation to adapt the existing means towards attaining predetermined ends (Willoughby, 2014, pp.178-179).

How does the model explain the emerging evidence of the technological domain being the source of innovative solutions rather than scientific research (Dernis, 2016; Smirnov \& Willoughby, 2021)? Scientific activities aim to explain existing phenomena using testable hypotheses and predictions. The NG model postulates that no knowledge exists about a phenomenon (or an artefact that enables it) before the novelty synthesis is completed. This technological activity is explorative experimentation and represents the synthesis of a novel phenomenon or an artefact according to the NG model. Only after this synthesis is over, scientific activity engages in the evaluation and understanding of novel phenomena. In short, technology precedes science because technology synthesises new phenomena, and science works to understand them. One can not understand what does not exist.

An essential comment must be made here for definitional acuity. Many scientists employ the methods of engineers to develop novelties. Does this change the implications stated above? The choice of terminologies such as technology and science might not be ideal. However, it does not change how different activities are to form novel phenomena (e.g. to perform activities defined by the NG model) and actions to understand them (e.g. to construct testable explanations). Technologists, engineers, and designers often do not perform the former type, which does not seek to explain. Scientists more often than not carry out the 
latter type, which cannot work without a phenomenon to observe. So, my usage of the terms technology and science inherently focuses on the essence of related and most frequent activities and is not concerned with labels.

An attentive reader might still argue that it is not apparent why science should necessarily follow technology in the genesis of novelty. Let us consider a crude but illustrative example. I will use the predictions of the NG model to clarify the relation between technology and science. Arguably, yet commonly accepted, science began with observations of stars in the skies by ancient Egyptians. We will omit for a moment the fact that the stars had to be formed first to be observable. The knowledge of those observations was described by Egyptians using a numbering system. This scientific knowledge would be used to build pyramids aligned accurately with the movement of the celestial bodies. The intuition suggests that science preceded the formation of novelty, in this instance - the pyramids. However, according to the NG model, this knowledge would be only one component of the construction process among many, such as stones, fixing mechanisms, supporting structures and many others. Understanding how stars move in the sky would be insufficient to understand the pyramids.

Furthermore, the designers of pyramids would not be able to directly use this knowledge for the construction because this knowledge was a stable component. They would need to separate specific and unstable knowledge elements appropriate for solving particular problems in pyramid design and construction. This selective effort does not follow from the knowledge of stars observations.

In addition, the input of energy and many experimentations would be necessary to recombine unstable components into a novel structure with a different linking mechanism. As a result, the novel design (pyramids) would represent a significant transition of scientific knowledge about the star movement. Observations of the sky itself would be incapable of explaining this transition. A different scientific investigation would be necessary to understand the construction of one of the Wonders of the World. The scientific knowledge is insufficient to explain a novelty even if this knowledge was used during the novelty genesis. While novelty formation results from technological activities, a new scientific inquiry is necessary to understand the resulting novelty. In short, the NG model postulates that scientific knowledge about the novelty necessarily follows the technical process of forming the novelty.

\subsection{Future research and limitations}

The NG model offers a succinct, testable and logically coherent explanation of novelty synthesis. Its elements and their interactions are clearly expressed in Fig. 4. Theoretical underpinnings of the NG model are well-grounded in existing knowledge about systems with conserved properties (energy and mass). Thus, it provides a logical structure to the novelty formation process. This study has several limitations. First, theory validation with more case studies is necessary. Second, to ground better the 
findings of this study in domain theory and explain various implications for innovation activities, more conceptual work is needed. Third, this paper has used a qualitative approach to case studies. Future work should focus on a research design that would employ quantitative analysis. Lastly, the process of novelty genesis is similar to the chemical reactions. Future work can apply the knowledge and theories of chemistry to refine the NG model and offer quantitative tools for further research and understanding of novelty.

\subsection{Recommendations to use the NG model}

The NG model suggests that for a preconceived product, one should have a clear understanding of five essential elements of the novelty genesis:

1. Components;

2. A linking mechanism;

3. Energy inflows;

4. Environmental forces;

5. Synthesis instructions.

The model postulates that a non-obvious process that causes the transition from the old to the new is forming a new linking mechanism between destabilised components under the inflow of energy. It is not enough to combine old and stable elements in a new way. One should separate essential sub-parts of those old elements and prepare or destabilise them for recombination to achieve a product, which is stable under environmental forces.

A familiar example of this process is a brainstorming session (Fig. 6). Participants (stable components) contribute their expertise. Contingent ideas (unstable components) that each participant offers during the initial brainstorming stage are extensions of the participant's expertise. The list of ideas on the board of the room (confinement) now gets manipulated through the leader of the session (catalyst) by controlling two types of efforts (energy inflows). One effort comes from the session leader, who recombines the components on a board and finds a creative combination. Another effort comes from leading the participants to process the original list and produce novel ideas by simultaneous recombination of original ideas inside their heads. The genesis of novelty would occur when ideas are recombined in a new configuration through a particular linking mechanism, resulting in a whole new idea. The session completes when participants believe that the result represents a novel idea that will be functional and valuable (selective forces of the environment). 




Fig. 6. Application of the NG model to analyse a brainstorming session.

\section{Conclusions}

This conceptual paper aimed to advance the theory of innovation processes by building new theoretical perspectives on novelty formation from case study research. The introductory section offered the analysis of innovation process and creativity models to understand the phenomenon of novelty genesis. The results indicated that the conceptualisation of this crucial phenomenon in the innovation and creativity theory at present is scarce and inadequate. This article proposed to study several familiar cases of creative acts and build a theoretical model by conceptualising the results of case research. Five cases of novel creations were selected that go beyond the mere generation of cognitive artefacts and represent creations in the physical world. Cross-case patterns and similarities were identified, and the novelty genesis model was conceptualised. The theoretical underpinnings of the novelty genesis model were compared with extant theories in innovation and creativity literature to examine the main similarities, contradictions, and reasons. Future work should be focused on further validation and conceptualisation of the findings. This paper aimed at answering the question, what is the underlying mechanism of novelty genesis? A simple answer that follows from the results, novelty is a structural transition of input components to a new product, stable under the environmental forces. This transition occurs due to the experimentation with different component combinations and a linking mechanism under the inflow of energy guided by creational instructions.

\section{Acknowledgements}

I would like to thank Zeki Can Seskir from the Physics Department of the Middle East Technical University for instructive comments on the early draft of this paper. 
Word count: 10250 words, excluding abstract, figures, tables and references.

\section{References}

Astebro, T., 2004. Key success factors for technological entrepreneurs' R\&D projects. IEEE Transactions on Engineering Management, 51(3), pp.314-321. https://doi.org/10.1109/TEM.2004.830863

Baradaran, M.S., Yadollahi Farsi, J., Hejazi, S.R. and Akbari, M., 2019. A Competency-based Typology of Technology Entrepreneurs: A Systematic Review of the Empirical Studies. Iranian Journal of Management Studies, 12(2), pp.191-211. https://dx.doi.org/10.22059/ijms.2019.241656.672822

Bates, K.A. \& Flynn, E.J., 1995. Innovation history and competitive advantage: A resource-based view analysis of manufacturing technology innovations. In: Academy of Management Proceedings, 1995(1), pp. 235-239. https://doi.org/10.5465/ambpp.1995.17536502

Boden, M.A., 2004. The creative mind: Myths and mechanisms. Routledge.

Bush, V., 1945. Science - The Endless Frontier: A Report to the President on a Program for Postwar Scientific Research, United States Government Printing Office, Washington, DC.

Castonguay, Y., Cayrol, A. \& Hamouti, R., 2020. Success factors of a technological entrepreneurship project: a systematic review. Journal of Academy of Business and Economics, 20(3), pp. 141-154.

Debesay, J., Nåden, D. \& Slettebø, Å., 2008. How do we close the hermeneutic circle? A Gadamerian approach to justification in interpretation in qualitative studies. Nursing Inquiry, 15(1), pp.57-66. https://doi.org/10.1111/j.1440-1800.2008.00390.x

Definition of chemistry [online], 2021. Oxford's free English dictionaries. Oxford University Press. Available at: https://www.lexico.com/definition/chemistry (Accessed: 14 July 2021).

Dernis, H., Squicciarini, M. \& de Pinho, R., 2016. Detecting the emergence of technologies and the evolution and codevelopment trajectories in science (DETECTS): a 'burst' analysis-based approach. The Journal of Technology Transfer, 41(5), pp.930-960. https://doi.org/10.1007/s10961-015-9449-0

Dieter, W. and Schmitt, W., 2018. A Literature Review on Innovation Process. East African Scholars Journal of Economics, Business \& Management, 1(03), pp.64-71.

Eisenhardt, K.M., 1989. Building theories from case study research. Academy of management review, 14(4), pp.532550. https://doi.org/10.5465/amr.1989.4308385

Eveleens, C., 2010. Innovation management; a literature review of innovation process models and their implications. Unpublished manuscript, pp.1-16.

Evers, N. \& Andersson, S., 2021. Predictive and effectual decision-making in high-tech international new venturesA matter of sequential ambidexterity. International Business Review, 30(1), p.101655. https://doi.org/10.1016/j.ibusrev.2019.101655

Gross, D.J., 1996. The role of symmetry in fundamental physics. Proceedings of the National Academy of Sciences, 93(25), pp.14256-14259. https://doi.org/10.1073/pnas.93.25.14256

Gupta, M., 2018. The innovation process from an idea to a final product: a review of the literature. International Journal of Comparative Management, 1(4), pp.400-421. https://doi.org/10.1504/IJCM.2018.096731

Herstatt, C. \& Verworn, B., 2004. Innovation process models and their evolution. In: Bringing Technology and Innovation into the Boardroom, pp. 326-346. Palgrave Macmillan, London. https://doi.org/10.1057/9780230512771_15

Jaakkola, E., 2020. Designing conceptual articles: four approaches. AMS Review, 10. pp.18-26. https://doi.org/10.1007/s13162-020-00161-0

Kline, S.J. \& N. Rosenberg, 1986. An overview of innovation. In R. Landau \& N. Rosenberg (eds.), The Positive Sum Strategy: Harnessing Technology for Economic Growth. Washington, DC: National Academy Press, pp. 275-305. https://doi.org/10.17226/612

Koestler, A., 1964. The act of creation. Hutchinson. 
Kotsemir, M., Abroskin, A. \& Meissner, D., 2013. Innovation concepts and typology-an evolutionary discussion. Higher School of Economics Research Paper, working paper BRP 05/STI/2013, http://dx.doi.org/10.2139/ssrn.2221299

Kraay, KJ, 2008. Creation, actualisation and God's choice among possible worlds. Philosophy Compass, 3(4), pp.854872. https://doi.org/10.1111/j.1747-9991.2008.00159.x

Lopes, A.P., Kissimoto, K.O., Salerno, M.S., Laurindo, F.J. \& Carvalho, M.C., 2012. Innovation management: a literature review about the evolution and the different innovation models. In: International Conference on Industrial Engineering and Operations Management, ID324.1-ID324.8.

McPhee, C., Giones, F., \& Dutta., D. K. 2019. Editorial: Technology Commercialisation and Entrepreneurship. Technology Innovation Management Review, 9(1), pp. 3-8. http://doi.org/10.22215/timreview/1207

Meissner, D. \& Kotsemir, M., 2016. Conceptualising the innovation process towards the active innovation paradigm'-trends and outlook. Journal of Innovation and Entrepreneurship, 5(1), pp.1-18. https://doi.org/10.1186/s13731-016-0042-z

Mendoza-Silva, A., 2020. Innovation capability: a systematic literature review. European Journal of Innovation Management, 24(3), pp. 707-734. https://doi.org/10.1108/EJIM-09-2019-0263

Mintzberg, H., 1979. An emerging strategy of" direct" research. Administrative science quarterly, 24(4), pp.582-589. https://doi.org/10.2307/2392364

Nonaka, I., 1994. A dynamic theory of organisational knowledge creation. Organisation science, 5(1), pp.14-37. https://www.jstor.org/stable/2635068

Porter, M.E., 1997. Competitive strategy. Measuring business excellence. Porter, M.E., 1997. Competitive strategy. Measuring business excellence, 1(2), pp. 12-17. https://doi.org/10.1108/eb025476

Sarasvathy, S.D., 2001. Causation and effectuation: Toward a theoretical shift from economic inevitability to entrepreneurial contingency. Academy of management Review, 26(2), pp.243-263. https://doi.org/10.2307/259121

Schiller, F.C.S., 1930, January. Creation, emergence, novelty. In Proceedings of the Aristotelian Society (Vol. 31, pp. 25-36). Aristotelian Society, Wiley. http://www.jstor.org/stable/4544180

Shkliarevsky, G., 2017. Understanding the process of creation: A new approach. Management: Journal of Sustainable Business and Management Solutions in Emerging Economies, 22(3), pp.1-13. https://doi.org/10.7595/management.fon.2017.0021

Smirnov, D. \& Golkar, A., 2015. Stirling engine systems tradespace exploration framework. Procedia Computer Science, 44, pp.558-567. https://doi.org/10.1016/j.procs.2015.03.010

Smirnov, D. S., \& Willoughby, K. W., 2021. Rethinking the Dynamics of Innovation, Science, and Technology: The Curious Case of Stirling Engines and Stirling Refrigerators. Energy Research \& Social Science. Forthcoming.

Smirnov, D., \& Golkar, A., 2019. Design optimisation using game theory. IEEE Transactions on Systems, Man, and Cybernetics: Systems, 50(2). https://doi.org/10.1109/TSMC.2019.2897086

Smirnov, D., Dvortsov, V., Saichenko, A., Tkachenko, M., Kukolev, M., Bischi, A., \& Ouerdane, H. (2019). Experimental study of a high-tolerance piston-cylinder pair in the alpha Ross-yoke Stirling refrigerator. International Journal of Refrigeration, 100, pp. 235-245. https://doi.org/10.1016/j.ijrefrig.2019.01.018

Sossa, J.W.Z., Rebolledo, J.L.S., Hincapié, J.M.M. and Zarta, R.H., 2019. Innovation management models-A literature review. International Journal of Innovation, Creativity and Change, 10(6), pp. 175-194. http://hdl.handle.net/11407/5822

Sweller, J., 2009. Cognitive bases of human creativity. Educational Psychology Review, 21(1), pp.11-19. https://doi.org/10.1007/s10648-008-9091-6

Truhlar, D.G., Garrett, B.C. and Klippenstein, S.J., 1996. Current status of transition-state theory. The Journal of physical chemistry, 100(31), pp.12771-12800. https://doi.org/10.1021/jp953748q

Tushman, M.L. \& Murmann, J.P., 1998. Dominant Designs, Technology Cycles, and Organization Outcomes. Academy of Management Proceedings, 1998(1), pp. A1-A33. https://doi.org/10.5465/apbpp.1998.27643428 
Utterback, J.M., 1971. The process of technological innovation within the firm. Academy of Management Journal, 14(1), pp.75-88. https://doi.org/10.2307/254712

Walia, C., 2019. A dynamic definition of creativity. Creativity Research Journal,31(3), pp.237-247. https://doi.org/10.1080/10400419.2019.1641787

Whale, J., 1931. Frankenstein, Carl Laemmle Jr., Film.

Willoughby, K.W., 2014. What can be patented? Confronting the confusion in patent law about patent-eligible subject matter, Scholars Press, Saarbruecken. 